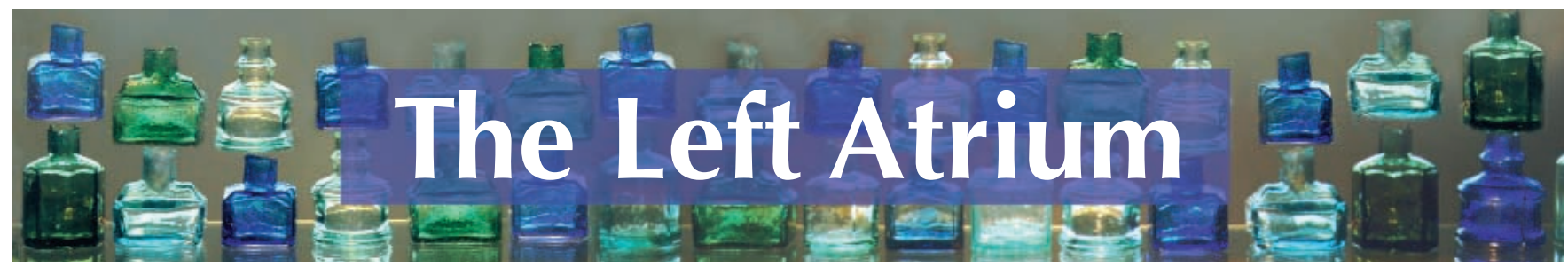

\section{Considering the state of the world}

Global crises, global solutions

Edited by Bjørn Lomborg

Cambridge: Cambridge University Press; 2004

700 pp \$39.95 ISBN 0-521-60614-4

$\mathrm{H}$ aving trouble thinking clearly about the state of the world? Global Crises, Global Solutions, edited by Bjørn Lomborg, may help you think in a more orderly fashion about this complicated topic. The book came to my attention as I was gazing down from 36000 feet at a quiescent Mexican volcano. My in-flight reading material that day included copies of Scientific American and The Economist. Both periodicals carried reviews of the book. I was intrigued by the book's title; I wondered how many of the 10 crises singled out for discussion in this volume were health related, and specifically if any of these could be considered major Canadian crises.

Lomborg is Associate Professor of Statistics at the University of Aarhus in Denmark. In 2002, while he was Director of the Environmental Assessment Institute, he and colleagues put forward the idea of having internationally recognized economists do a "dollars-andsense" prioritization of the biggest challenges facing the world.

This idea eventually became the Copenhagen Consensus project and was carried out during 2003 and 2004, concluding with a week-long conference in the Danish capital. According to Lomborg, "The core idea is simple: with scarce resources to tackle the problems of the world, prioritization is necessary." It's not a particularly radical idea: substitute "Canadian health care" for "the world," and you will recall recent commissions and inquiries that have defined and prioritized the big challenges in providing health care to Canadians.

Lomborg notes the parallel between prioritizing activities at the global level and in the health care arena:
Many people have criticized this project - that prioritization should be necessary at all. Yet, imagine if doctors at an overstretched hospital refused to perform triage on outpatients, but instead coped with patients as they arrived, focusing more attention on those whose families made the most fuss. We would never accept such an approach in the hospital the approach would be unjust, waste precious resources and cost lives. We should not accept it for the rest of the world either.

The Copenhagen Consensus is not about finding the cash to address the priorities, or about deciding what would be an appropriate level of investment. The focal question, according to Lomborg, is "Where should the world invest, say, $\$ 50$ [billion] extra over the next four years to do the most good?"

The book is neatly organized. Preliminary focus groups and recent UN documents were used to choose the 10 major crises. For the Copenhagen conference, various experts were invited to prepare substantial perspective papers on each issue; these papers form the bulk of the text. Other specialists

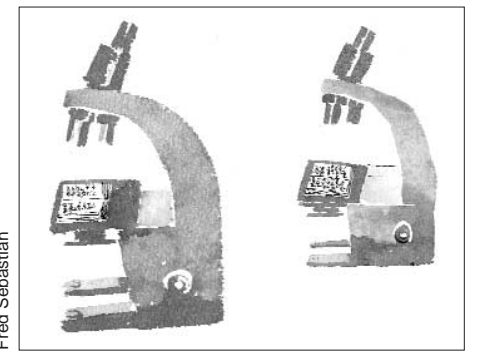
contributed alternative perspectives. In the final section of the book the expert panel of economists ranks the various proposals put forward in the perspective papers.

The 10 challenges are: climate change; communicable disease; conflicts; access to education; financial instability; governance and corruption; malnutrition and hunger; migration; sanitation and access to clean water; and subsidies and trade barriers. Thus, three of the ten crises do directly concern health. All the global problems described are pertinent to the Canadian scene; however, their impact on most Canadians' quality of life is modest.

For instance, major Canadian health care challenges in 2005 appear (in the media, at least) to include the rising health costs associated with aging babyboomers, the recent Supreme Court ruling against Quebec's prohibition on private health insurance, and the shortage of health care professionals. In the area of communicable diseases, Canadians are in the relatively advantageous position of dealing with small numbers of West Nile virus or $C$. difficile infections rather than with endemic malaria and HIV. We worry more about obesity than hunger, and our major water issue, Walkerton aside, pertains to the potential sale of abundant clean water rather than the shortage of it. Canadian crises are not insignificant, but they are vastly less urgent than those in the developing world.

Global Crises, Global Solutions is rich in data; the chapters are accompanied by copious figures, tables and appendices. "At any given time close to half the population in developing countries suffer from one or more water[borne] diseases." Every week 15000 more people become infected with HIV. "It is estimated that ... 162 million pre-school children and almost a billion people of all ages are malnourished." Despite the abundance of such dismaying statistics, many of the writers also comment on the paucity of quality research into the various issues, with the attendant difficulty of making reliable cost-benefit analyses.

In the midst of all these statistics, one question pops up repeatedly: What 
is the value of statistical life (VSL)? To consider issues within a cost-benefit framework, one has to assign a value to a human life. Christian Friis Bach, spokesperson for the Youth Forum that ran concomitantly with the Copenhagen conference, speaks to this issue:

We already price human beings differently, when we carry out heart surgery in rich countries (which is extremely costly) but fail to save children in Africa who die of malaria (although the cost of doing so is cheap). The evidence presented during the week in Copenhagen showed that it really pays to invest in poor people in poor countries. Thus, the price of a life in Africa, Asia or Latin America went up. This is perhaps the most important outcome of the Copenhagen Consensus conference.

Four proposals are ranked by the panel of economists as potentially very good investments. The double opportunity to bring HIV/AIDS and malaria under control is assigned a high priority. Trade liberalization (not to be mistaken for free trade) receives a high ranking as one response to the crisis of subsidies and trade. With regard to confronting malnutrition and hunger, the economists see a greater opportunity in the provision of micronutrients to people than in the development of new agricultural technologies (rated "good"), or improving infant and child nutrition (rated "fair").

There is a danger in reading books like Global Crises, Global Solutions that they may fuel a sense of complacency about our situation at home and a feeling of futility about trying to work for change abroad. Assigning priorities personally, professionally and globally seems inherently to be a good idea. But what if action is not forthcoming? Jacques van der Gaag, in his perspective on communicable diseases, asks a more trenchant question: "Why, when resources are available, technology exists and national and international awareness is high, is so little done in the lightoे of so much human suffering and potential economic loss?"

\section{Vincent Hanlon}

Emergency Physician

Lethbridge, Alta.

\section{Dyspnea}

It's very late in the NICU. I push on the resuscitation room door, so weary I can Ibarely open it. I look inside the room, and then I gasp. My fatigue is gone, replaced by anxiety and euphoria. There she is.

$I^{\prime} m$ in love with a respiratory therapist.

We're waiting for a 28 -weeker in the middle of the night. We chat about nothing much. She's funny, her humour dry and brainy, but when I try to laugh there's just this nervous wheeze.

The baby is delivered and does well at first, but soon needs more oxygen.

"What do you want to do?" the neonatologist says to me. I'm surprised to hear him speak. I've forgotten about him, forgotten that he's even in the room. "Do you want to give surfactant?"

Glancing at the monitor, I see a falling oxygen saturation. Then I look at the RT. She nods slightly. At least I think she nods. That's good enough for me.

"Okay, let's give surfactant," I say, and then I ask for the meds that the baby will need before being intubated. While everything is being prepared, she asks me to go through the equipment I'Il need to intubate. I get it right, and she gives me a smile that somehow causes a partial obstruction of my trachea.

The baby is given some drugs and then I ventilate with a bag and mask for a while. I pick up the laryngoscope and have a look. There's mucus everywhere, even after I suction. Dammit! Flushing red with tachypnea, I look up at her as I start bagging again.

I try again with the laryngoscope, and I think I see the cords. But when I put the tube in, the baby gags. The tube's in the esophagus. And the drugs are wearing off. Oh, for Christ's sake! I put the mask back on, looking at the baby the whole time. I'm too embarrassed to show her my face, blue from apnea.

"Try one more time," says the neonatologist.

By now, the baby is putting up a fight. Although it's tricky getting the laryngoscope in, I manage it. But I can't see anything.

"Maybe you should pull back a little," she says, her voice slightly deep and vastly calm. I withdraw the blade; a tiny epiglottis and tiny vocal cords pop into view. The tube goes in, and the baby gets some surfactant. Hooray! I step out of the way so she can set up the ventilator.

I watch her work. She's quick and precise. I'm in awe of her grace. I realize that I'm staring, so I walk away to write some orders.

She finds me a few minutes later. "Good job with that intubation," she says. "It looked like a tough one." She just complimented me! Stuporous from hypoxia, I barely manage to thank her.

Later, the family comes in, and I show them around their baby. I explain what the ventilator and the warmer are for. I discuss the numbers on the monitor. I talk about what they should expect for the next little while. I assure them that their baby, for being so premature and so little, is doing well.

I'm about to go back to my call room when she says, "You know, you've got a really good bedside manner."

A compliment! Another one! Anoxia strikes some important parts of my brain, and I can't even attempt speech. Grinning mutely and foolishly, I excuse myself.

Back in my call room, I collapse. In the morning I'Il realize that I've just successfully intubated a neonate for the first time. But for now I can only wait for my lungs to inflate so that I can fall asleep and dream of her quiet breath.

\section{Paul Moorehead}

Pediatrics Resident

Memorial University of Newfoundland

St. John's, Nfld. 